\title{
An online survey of young adolescent girls' use of the internet and smartphone apps for mental health support
}

Rebecca Grist, Bethany Cliffe, Megan Denne, Abigail Croker and Paul Stallard

\section{Background}

Adolescents are digital natives, with the majority now owning their own smartphones and having internet access. Although the internet and smartphone applications (apps) can provide mental health support, little is known about how young adolescents use digital technology for mental health purposes. There are many digital health resources available for young people, but the assumption that they will be open to use them has been largely untested.

\section{Aims}

We aimed to explore how adolescents with and without raised symptoms of anxiety, depression and problematic eating use the internet on smartphones/tablets and mental health apps.

\section{Method}

The Bristol Online Survey tool was used to deliver an online survey to 775 girls aged $11-16$ years, attending a state-funded secondary school in the south-west of England. The survey was completed in class during the winter term of 2017.

\section{Results}

A total of 98.7 and $97.4 \%$ used the internet and apps, respectively, although only $6 \%$ had used any mental health apps. Of those with raised mental health symptoms, $15-17 \%$ used or were using a mental health app, with $48.5 \%$ reporting that they would not use a mental health app.

\section{Conclusions}

Young female adolescents are avid users of the internet and apps but are not using digital technology for mental health purposes. Addressing concerns about digital technology are necessary to maximise the effect it can have on child and adolescent mental health.

\section{Declaration of interest}

None.

\section{Keywords}

Information technologies; stigma and discrimination; primary care.

\section{Copyright and usage}

(c) The Royal College of Psychiatrists 2018. This is an Open Access article, distributed under the terms of the Creative Commons Attribution-NonCommercial-NoDerivatives licence (http:// creativecommons.org/licenses/by-nc-nd/4.0/), which permits non-commercial re-use, distribution, and reproduction in any medium, provided the original work is unaltered and is properly cited. The written permission of Cambridge University Press must be obtained for commercial re-use or in order to create a derivative work.
Mental health problems among children and adolescents are common, with at least one in five suffering from a mental health disorder. ${ }^{1}$ These disorders often persist, with a New Zealand based study finding that $50 \%$ of young adults develop mental health problems before age 15 years and $74 \%$ before age 18 years. ${ }^{2}$ Child mental health problems cause significant distress and impairment and increase the probability of adverse psychosocial outcomes and subsequent mental health problems in young adulthood. ${ }^{3,4}$

Effective interventions for young people with anxiety disorders, depression and eating disorders are available. ${ }^{5-7}$ However, less than one-quarter of children with mental health problems in the UK and the USA ever receive specialist treatment. ${ }^{8,9}$ To have a positive effect on child mental health, alternative ways of providing mental health support are required.

\section{Digital technology}

The omnipresence of technology in everyday life has led the National Health Service (NHS) to explore how digital technology can be used to help individuals to manage their health. ${ }^{10}$ Providing or augmenting evidence-based interventions with digital technology offers an innovative solution and may be particularly salient to young people. In the UK in 2016, 98\% of children and adolescents had access to the internet, $83 \%$ of 12 - to 15 -year-olds had their own smartphone and $55 \%$ had their own tablet. ${ }^{11}$ The convergence of healthcare with technological devices comprises 'digital health', with one particular area, smartphone applications (apps), seeing rapid growth. ${ }^{12,13}$ The functions of these apps vary: some provide a platform through which individuals can receive therapy and access peer support, whereas others provide information or contain tools such as mood monitoring or sleep diaries.

\section{Digital technology for mental health}

Smartphone apps offer a low-cost option for increasing availability and access to mental health information and support for adolescents. However, this is based on a largely untested assumption, namely that adolescents will embrace the use of digital technology for mental health purposes. ${ }^{14}$ One of the few studies to investigate this question found that only $16 \%$ of an Australian community sample of older adolescents (aged 15-19 years) expressed a preference for online mental health interventions. ${ }^{15}$ Similarly, in a Canadian community sample of young adults (aged 17-24 years), $77 \%$ reported that they were unlikely to use social media websites for mental health help-seeking or information. ${ }^{16}$ Few studies have explored the use of digital technology or apps for mental health purposes in young adolescents ( $\leq 18$ years of age). Understanding young people's use of, and attitudes toward digital technology is important if the potential benefits of this can be harnessed to have a positive effect on mental health.

The current study aims to address this shortfall and will (a) ascertain the content and purpose of young adolescent girls' internet and app usage on smartphones and tablets; (b) explore their usage of, and perceived advantages and disadvantages of 
using mental health apps and (c) explore the mental health internet and app use of those with raised symptoms of anxiety, depression or problematic eating.

\section{Method}

\section{Design}

This was an opportunistic cross-sectional study. All $(n=876)$ adolescent girls, aged 11-16 years and attending a UK state-funded secondary school were invited to participate in an online psychological well-being and technology use survey. The online survey was constructed with the secure Bristol Online Survey platform. Participants completed the survey individually during a physical health and social education lesson during the winter term of 2017.

\section{Psychological screening}

Anxiety and depression was determined by the Hospital Anxiety and Depression Scale (HADS). ${ }^{17}$ The HADS is a commonly used brief screening of anxiety and depressive symptoms. It consists of 14 items rated on a four-point scale ranging from 0 (not at all) to 3 (a great deal of the time), with 3 indicating higher symptom frequency. HADS has two subscales, with seven items measuring anxiety and seven items assessing depression. The total score on each subscale ranges from 0 to 21 , and score ranges are classified as normal (0-7), mild (8-10), moderate (11-14) or severe (1521 ). With children and young people, a score of $\geq 10$ for depression and $\geq 12$ for anxiety is optimal for minimising false negatives. ${ }^{18}$ The HADS has demonstrated acceptable validity and has been validated for use with adolescents. ${ }^{18}$

Problematic eating was determined by the SCOFF. ${ }^{19}$ The SCOFF is a brief screening scale assessing five core symptoms of anorexia and bulimia nervosa. Respondents are asked to rate each of five symptoms (vomiting, loss of control over eating, weight loss, body distortion and food domination) as true for them or not. Each positively endorsed item is scored 1, with a total score of 2 or more suggesting a probable eating problem. The SCOFF has been validated with adolescents ${ }^{20}$ and shows good sensitivity $(100 \%)$ and specificity (87.5\%). Question three, 'Have you recently lost more than 1 stone in a 3-month period?', was adapted to include kilograms and pounds ( $6.30 \mathrm{~kg}$ is equal to 14 pounds, or 1 stone) to assist adolescents to interpret their weight.

\section{Technology use and attitudes toward mental health apps questionnaire}

Eleven questions were developed to assess smartphone/tablet internet use and habits, utilisation of mobile apps and attitudes toward use of mobile apps for mental health purposes. Questions measured how long respondents spent online (in hours) and the kinds of activities they used their internet and smartphone apps for. Acceptability of mental health apps were measured by asking whether they had ever used mental health apps, would they use a mental health app if they needed help and what they perceived to be the advantages and disadvantages of using them. The survey items are provided in the supplementary material available at https://doi.org/10.1192/bjo.2018.43.

\section{Ethics and consent}

The study was approved by the Research Ethics Approval Committee for Health (REACH) at the University of Bath (REACH reference EP 16/17 127). Consent from the Headteacher was obtained for school-level recruitment to take place. Once this was agreed, parents and guardians were sent a letter informing them of the survey, and inviting them to opt their child out if they did not want them to be involved. Students were then required to provide assent before participation by reading the information sheet and assent form presented online before beginning the survey. Considering the sensitive nature of the questionnaire, the survey ended by providing links to local and national websites where the girls could obtain mental health support or information should they require it.

\section{Results}

\section{School profile}

The study school was based in a small town in a relatively affluent area. The school was assessed as 'good' in their latest Ofsted inspection, a rating achieved by $79 \%$ of schools in $2017 .^{21}$ The school had fewer pupils $(0.9 \%)$ with a statement of special educational needs or education, health and care compared with a national average of 4.3\%. Similarly, fewer (5.8\%) were eligible for free school meals (national average of $13.2 \%$ ) and $6.5 \%$ did not speak English as their first language (national average of $16.1 \%$ ). These statistics suggest that this school is less disadvantaged than the national average.

Academically, the school was performing better than the national average. In 2017, 39\% of pupils achieved grade 5 or above in English and Maths (national average of 19.6\%). The school had an overall absence rate of $5 \%$ and a persistent absence rate (i.e. missing $10 \%$ or more of the morning or afternoons they could attend) of $13 \%$, comparable to a national average absence rate of $5.4 \%$ and a persistent absence rate of $13.5 \%$.

\section{Internet use on smartphone/tablet}

A total of 775 students from years 7-11 (aged 11-16 years) completed the survey, representing $88.5 \%$ of the total school population. All but ten students $(1.3 \%)$ reported using the internet on their smartphone or tablet. The average reported amount of time spent on the internet each day was $3.8 \mathrm{~h}($ s.d. $=1.66)$. Just over onethird of girls $(n=288,37.2 \%)$ spent $\geq 5$ h each day on the internet.

Participant responses to the question 'What do you mostly use your smartphone/tablet for?' are summarised in Table 1. The main activities relate to social communication (texting and social networking) and entertainment (streaming music and films and gaming).

\section{App use}

Most students reported that they used apps $(n=755,97.4 \%)$ with $640(84.9 \%)$ having six or more apps installed on their phone.

$\begin{array}{lc}\text { Table } 1 \quad \text { Smartphone and tablet use } & \\ \text { What smartphone/tablet is used for } & N(\%) \\ \text { Texting and calling } & 665(85.8) \\ \text { Downloading or streaming music, TV shows, films } & 509(65.7) \\ \text { Social networking (blogs, chat rooms, forums, social } & 485(62.6) \\ \quad \text { networking sites) } & \\ \text { Playing games } & 472(60.9) \\ \text { Browsing the internet for entertainment or lifestyle purposes } & 430(55.5) \\ \text { Online shopping } & 422(54.5) \\ \text { Using apps } & 374(48.3) \\ \text { Browsing the web for information or general purposes } & 265(43.2) \\ \text { Email } & 193(24.9) \\ \text { Travel and navigation (e.g. Google maps, travel timetables) } & 162(20.9) \\ \text { Reading news, online magazines and newspapers } & 152(19.6) \\ \text { Reading eBooks or listening to audio books } & 114(14.7) \\ \text { Other } & 63(8.1)\end{array}$


Table 2 Types of apps installed on their smartphone/tablet

What types of apps do you have?

Watching films and TV (e.g. Netflix, Vivo, YouTube)

Music streaming (e.g. Spotify)

Social networking (e.g. Snapchat, Facebook)

Entertainment (emojis, colouring, podcasts, video editing)

Gaming (e.g. Pokémon, Angry Birds)

Shopping (e.g. eBay, Amazon)

Education e.g. (language, driving theory, school work)

Lifestyle (e.g. beauty, fashion, crafts, photography)

Health and fitness (healthy living, exercise, activities)

Travel and navigation (Google maps, transport times)

News, magazines and newspapers (e.g. Buzzfeed, BBC)

Food and drink (takeaways, recipes, cooking)

Reading eBooks or listening to audio books

Mental health (e.g. mood trackers, self-help, interventions)

Physical health (medical education and management)

Reference (game cheats, Wikipedia, thesaurus)

Other
$N(\%)$

$385(49.7)$

$340(43.9)$

329 (42.5)

328 (42.3)

$327(42.2)$

$220(28.4)$

$212(27.4)$

$147(19.0)$

$127(16.4)$

$110(14.2)$

88 (11.4)

85 (11.0)

$79(10.2)$

$44(5.7)$

$42(5.4)$

$41(5.3)$

$10(1.3)$
The majority of apps were used fairly regularly, with 590 (78.2\%) reporting that they used four or more apps each week. A total of $500(66.3 \%)$ girls identified one to five apps that they had not used over the past 3 months. The types of apps are summarised in Table 2. As with internet use, the apps were primarily focused around entertainment, watching media, listening to music, gaming and social communication.

\section{Mental health apps}

Just over half ( $n=396 / 755,51.2 \%$ ) of the girls positively endorsed the statement 'If you had a mental health problem and there were apps available to help would you use them?' Potential advantages and disadvantages of using mental health apps are summarised in Table 3. Advantages of not having to talk to someone face to face, privacy and availability of help whenever required were identified most often. In terms of disadvantages, there were concerns about the accuracy of the information contained in the app and whether unauthorised people would be able to access information saved on the app. Finally, there were a total of $344(44.4 \%)$ young people who either felt that apps would not help them and/or would prefer a face-to-face rather than digital intervention.

\begin{tabular}{|c|c|}
\hline & $N(\%)$ \\
\hline \multicolumn{2}{|l|}{ Advantages } \\
\hline Anonymous - I don't have to talk to someone face to face & $502(64.8)$ \\
\hline Privacy - It is more private & $503(64.9)$ \\
\hline Availability - It will always be there when I need it & $439(56.5)$ \\
\hline Personal - It is personal to me & $399(51.5)$ \\
\hline $\begin{array}{l}\text { Accessible - I can get support and information whenever I } \\
\text { need it }\end{array}$ & $408(52.6)$ \\
\hline Instant - I don't have to wait to get information & $322(41.5)$ \\
\hline $\begin{array}{l}\text { Convenience - I don't have to write things like my mood } \\
\text { down on paper }\end{array}$ & $300(38.7)$ \\
\hline Other & $24(3.1)$ \\
\hline \multicolumn{2}{|l|}{ Disadvantages } \\
\hline $\begin{array}{l}\text { Accuracy - I don't know whether the information is accurate } \\
\text { or true }\end{array}$ & $507(65.4)$ \\
\hline $\begin{array}{l}\text { Unauthorised access - I am afraid someone will see the app } \\
\text { on my phone }\end{array}$ & $438(56.5)$ \\
\hline Cost - It might cost money & $375(48.4)$ \\
\hline Trust - I don't trust apps & $295(38.1)$ \\
\hline Ineffective - I don't believe they would help me & $229(29.5)$ \\
\hline Impersonal - I would prefer to speak to someone face to face & $179(23.1)$ \\
\hline Other & $16(2.1)$ \\
\hline
\end{tabular}

\section{Mental health and app use}

Mean scores on the HADS were 9.87 (s.d. $=4.45$ ) for the anxiety subscale, 5.47 (s.d. = 3.55) for the depression subscale and 15.34 (s.d. = 7.13) for the total scale. A total of 274 (35.4\%) girls scored above the cut-off $(\geq 12)$ for moderate/severe anxiety and 103 (13.3\%) scored above the cut-off for moderate/severe depression $(\geq 10)$. A total of $306(39.5 \%)$ girls positively endorsed two or more items on the SCOFF, suggesting a probable eating problem. Just over half of the sample ( $n=398 / 755,52.7 \%)$ had raised symptoms of anxiety and/or depression and/or problematic eating.

A comparison of those scoring above the cut-off for anxiety, depression and problematic eating and their response to using mental health apps are summarised in Table 4. Within this symptomatic group, only $5.7 \%$ of girls had used the internet for mental health purposes. Although $51.5 \%$ of girls reported that they would use an app if they had a mental health problem, only $16.1 \%$ of had actually used one, and $44.3 \%$ of this symptomatic group did not think an app would help them and/or expressed a preference for face-to-face help.

\section{Discussion}

\section{Principal findings and comparisons with previous work} Internet use on a smartphone/tablet

Internet and smartphone use were widespread among young adolescent girls: 98.7 and $97.4 \%$ used the internet and apps respectively, spending an average of $26.6 \mathrm{~h}$ a week online. Although almost universally used by this population, the internet and apps were primarily used for social communication and entertainment rather than for health purposes; only $5 \%$ of girls had any physical health or mental health apps installed on their devices.

Overall, adolescent girls were divided in their views about whether they would use apps to access mental health help; $51 \%$ reported that they would use an app if they had a mental health problem and $49 \%$ reported that they would not. These rates are lower than those found in a community sample of young adults in Australia, where $76 \%$ expressed interest in using a mobile phone for mental health monitoring and management. ${ }^{22}$ Although those in our study with potential problems with anxiety, depression or eating were three times more likely than the whole group to have or to have used a mental health app, the majority were not using them to access help. Rates of app use were similar

Table 4 Responses for use of mental health apps by students scoring above the cut-off points for anxiety, depression and problematic eating

\begin{tabular}{|c|c|c|c|}
\hline & $\begin{array}{l}\text { HADS } \\
\text { anxiety, } \\
N(\%)\end{array}$ & $\begin{array}{c}\text { HADS } \\
\text { depression, } \\
N(\%)\end{array}$ & $\begin{array}{l}\text { SCOFF, } \\
N(\%)\end{array}$ \\
\hline $\begin{array}{l}\text { Use the internet for mental } \\
\text { health purposes }\end{array}$ & $14(5.1)$ & $4(3.9)$ & $14(4.6)$ \\
\hline $\begin{array}{l}\text { If I had a mental health } \\
\text { problem and apps were } \\
\text { available, I would use them }\end{array}$ & $143(52.2)$ & $43(41.7)$ & $155(50.7)$ \\
\hline $\begin{array}{l}\text { I don't believe an app would } \\
\text { help me }\end{array}$ & $73(26.6)$ & $34(33.0)$ & $95(31.0)$ \\
\hline $\begin{array}{l}\text { I would prefer a face-to-face } \\
\text { meeting than use an app }\end{array}$ & $61(22.3)$ & $23(22.3)$ & $74(24.2)$ \\
\hline $\begin{array}{l}\text { I have/or have used an app to } \\
\text { help with mental health } \\
\text { problems such as low } \\
\text { mood, anxiety or eating }\end{array}$ & $42(15.6)$ & $18(17.6)$ & $46(15.2)$ \\
\hline \multicolumn{4}{|c|}{ HADS, Hospital Anxiety and Depression Scale. } \\
\hline
\end{tabular}


for those with potential anxiety, depression and eating problems. The most common reasons for not using an app were a preference for a face-to-face intervention and the perceived limited effectiveness of an app, common barriers that have been noted in other community surveys in Australia. ${ }^{15,22,23}$ Developing apps and online services will therefore be unlikely to have a positive effect on the mental health of young adolescents until there is a greater understanding of their help-seeking preferences and attitudes and increased awareness of the potential benefits of online mental health advice and support. ${ }^{15}$

Although adolescents are highly familiar with, and regular users of technology, our findings question the assumption that they will therefore use digital technology to access mental health interventions and support. ${ }^{14,24}$ It has been previously suggested that the number of individuals open to digital health would increase as technology became more familiar. ${ }^{15}$ Although our findings are limited to a single survey, they do not suggest that young adolescent girls are more likely to engage with mental health apps than in previous years. If the internet and apps are to be widely used to deliver or support mental health interventions, then educational strategies providing high-quality and accessible information should be considered to promote their benefits. ${ }^{25}$

\section{Disadvantages and advantages of mental health apps}

Just under half of the girls expressed a preference for a face-to-face intervention as opposed to a digital one. Consistent with previous research, concerns about accuracy of the app information, unauthorised access, cost and trust were most commonly identified. ${ }^{14}$ Worries about others seeing the app on their phone were raised by a significant number (56.5\%) of young people, highlighting the stigma associated with mental health and the need to maintain privacy. The accuracy of the information provided through the app was also identified as a concern. Many apps are developed and designed by a wide range of companies with a financial interest and with little professional input. There is, therefore, no guarantee that the information will be factually correct, based on effective psychological principles and best-practice guidelines. ${ }^{13}$

On the contrary, several advantages to using mental health apps were identified, including instant accessibility, availability and anonymity. ${ }^{14}$ The idea of help being readily available when needed and to have their own personal sources of help were positively noted. Privacy was also perceived as an advantage; girls noted that by using mental health apps they could keep their problems private from others and would not have to engage in face-to-face meetings.

In summary, participants in this study endorsed both advantages and disadvantages of digital technology, highlighting a range of perspectives and attitudes. It is important to acknowledge this variability and to avoid a 'one size fits all' approach. Although mental health apps can have clear benefits, young people's concerns need to be addressed before technological interventions are widely utilised by young adolescents.

\section{Limitations}

Our study is one of the first to report the views of young adolescent girls with and without elevated mental health symptoms, and their use of the internet and mental health apps. Although our findings are novel, we do acknowledge a number of limitations.

\section{Generalisability}

First, this was a cross-sectional study that sampled one UK school. This school was representative of others in the UK on some characteristics, but it was less deprived and was academically performing above the national average. Similarly, it was a girls' school and so we are unable to generalise these findings to young adolescent boys. Further, the setting of a girls' school may be different from that of a mixed gender school. This prohibits generalising these findings to girls outside of this specific school setting.

\section{Use of questionnaires}

Second, we relied on retrospective self-reporting and had no independent verification of internet and app use. Self-report questionnaires were used to screen for possible mental health issues and no diagnostic interviews were undertaken. Because of this, the issues identified within this sample of symptomatic girls cannot fully be generalised to a clinical population. Nonetheless, our data does provide an insight into the mental health app and internet usage of symptomatic girls - a group who may well benefit from an early online intervention.

\section{Mental health apps for children}

Third, we found a large discrepancy between those amenable to using mental health apps and those who actually used them. Similarly, these findings suggest that adolescents are less interested in mental health apps than adults. This may reflect the fact that the majority of mental health apps on the market are not developed specifically for young people with mental health problems. ${ }^{26}$ It is therefore unclear whether the lack of actual use is because of limited availability or rather concerns about the accuracy of the app data, privacy and security of personal information.

\section{Implications and future directions}

Digital and mHealth offer innovative opportunities to ease the burden on child and adolescent services as well as provide additional benefits such as anonymity, increased access and instant availability. Although it seems that around half of young people would be open to receiving support in this way, this study suggests that mental health apps are still not being widely utilised. Addressing concerns surrounding mHealth is vital to maximise the effect that they can have on child and adolescent mental health.

With regards to concerns about data protection and accuracy, the NHS has relaunched the app library that lists accredited apps for the public to view (see https://apps.beta.nhs.uk/). This could go some way to alleviating doubts around the trustworthiness of apps and the accuracy of the information provided. Further, as app stores can be very overwhelming because of the sheer volume of options, the NHS app library could be a useful point of reference to save time searching for evidence-based apps. There is also an ongoing need to better understand how young people use the internet and apps for mental health purposes. It is important to remember that, although young people are avid technology users, this is not an all-encompassing enthusiasm. To effectively target services and address concerns, further investigation is warranted to further explore their preferences and attitudes toward receiving mental health support in this digital age.

Rebecca Grist, Psychology Assistant, Department for Health, University of Bath, UK: Bethany Cliffe, Research Assistant, Department for Health, University of Bath, UK; Megan Denne, Clinical Research Assistant, Oxford Health NHS Foundation Trust, Child and Adolescent Mental Health Service, UK; Abigail Croker Clinical Research Assistant, Oxford Health NHS Foundation Trust, Child and Adolescent Mental Health Service, UK: Paul Stallard, Professor of Child and Family Mental Health, Department for Health,

University of Bath, UK and Head of Psychological Services, Oxford Health NHS Foundation Trust, Child and Adolescent Mental Health Service, UK

Correspondence: Paul Stallard, Department for Health, 6.10 Wessex House, University of Bath, Bath BA2 7AY, UK. Email: p.stallard@bath.ac.uk

First received 22 May 2018, final revision 12 Jun 2018, accepted 23 Jun 2018 


\section{Supplementary material}

Supplementary material is available online at https://doi.org/10.1192/bjo.2018.43.

\section{References}

1 Patel V, Flisher AJ, Hetrick S, McGorry P. Mental health of young people: a global public-health challenge. Lancet 2007; 369: 1302-13.

2 Kim-Cohen J, Caspi A, Moffitt TE, Harrington H, Milne BJ, Poulton R. Prior juvenile diagnoses in adults with mental disorder: developmental follow-back of a prospective-Iongitudinal cohort. Arch Gen Psychiatry 2003; 60: 709-17.

3 Woodward LJ, Fergusson DM. Life course outcomes of young people with anxiety disorders in adolescence. J Am Acad Child Adolesc Psychiatry 2001; 40: 1086-93.

4 Fergusson DM, Woodward LJ. Mental health, educational, and social role outcomes of adolescents with depression. Arch Gen Psychiatry 2002; 59: 225-31.

5 James A, James G, Cowdrey FA, Soler A, Choke A. Cognitive behavioural therapy for anxiety disorders in children and adolescents. Cochrane Database Syst Rev 2013; 3: CD004690.

6 National Institute for Health and Care Excellence (NICE). Depression in Children and Young People: Identification and Management (Clinical Guideline 28). NICE, 2017 (www.nice.org.uk/guidance/cg28).

7 National Institute for Health and Care Excellence (NICE). Eating Disorders: Recognition and Treatment. (Clinical Guideline 69). NICE, 2017 (https://www. nice.org.uk/guidance/ng69).

8 Merikangas KR, He J, Burstein M, Swendsen J, Avenevoli S, Case B, et al. Service utilization for lifetime mental disorders in U.S. adolescents: results of the national comorbidity survey-adolescent supplement (NCS-A). J Am Acad Child Adolesc Psychiatry 2011; 50: 32-45.

9 Ford T, Hamilton H, Meltzer H, Goodman R. Child mental health is everybody's business: the prevalence of contact with public sector services by type of disorder among British school children in a three-year period. Child Adolesc Ment Health 2007; 12: 13-20.

10 Mental Health Taskforce. Next Steps on the NHS Five Year Forward View. NHS England, 2017 (https://www.england.nhs.uk/wp-content/uploads/2017/03/ NEXT-STEPS-ON-THE-NHS-FIVE-YEAR-FORWARD-VIEW.pdf)

11 Office of Communications (Ofcom). Children and Parents: Media Use and Attitudes Report. Ofcom, 2015 (https://www.ofcom.org.uk/ data/assets/ pdf_file/0034/93976/Children-Parents-Media-Use-Attitudes-Report-2016.pdf).

12 IQVIA Institute for Human Data Science. The Growing Value of Digital Health in the United Kingdom. IQVIA, 2017 (https://www.iqvia.com/en/institute/reports/ the-growing-value-of-digital-health-in-the-united-kingdom).
13 Anthes E. Pocket psychiatry: mobile mental-health apps have exploded onto the market, but few have been thoroughly tested. Nature 2016; 532: 20-4.

14 Hollis C, Falconer C, Martin J, Whittington C, Stockton S, Glazebrook C, et al. Annual Research Review: digital health interventions for children and young people with mental health problems - a systematic and meta-review. J Child Psychol Psychiatry 2016; 58: 474-503.

15 Bradford S, Rickwood D. Adolescent's preferred modes of delivery for mental health services. Child Adolesc Ment Health 2014; 19: 39-45.

16 Wetterlin FM, Mar MY, Neilson EK, Werker GR, Krausz M. eMental health experiences and expectations: a survey of youths' web-based resource preferences in Canada. J Med Internet Res 2014; 16: e293.

17 Zigmond AS, Snaith RP. The Hospital Anxiety and Depression Scale. Acta Psychiatr Scand 1983; 67: 361-70.

18 White $D$, Leach $C$, Sims R, Atkinson M, Cottrell D. Validation of the Hospital Anxiety and Depression Scale for use with adolescents. Br J Psychiatry 1999; 175: 452-4.

19 Morgan JF, Reid F, Lacey JH. The SCOFF questionnaire: assessment of a new screening tool for eating disorders. BMJ 1999; 319: 1467-8.

20 Hansson E, Daukantaité D, Johnsson P. SCOFF in a general Swedish adolescent population. J Eat Disord 2015; 3: 48.

21 Office for Standards in Education (Ofsted). Ofsted Annual Report 2016/17 Data Summary. Ofsted, 2017 (https://www.gov.uk/government/publications/ ofsted-annual-report-201617-education-childrens-services-and-skills/ofstedannual-report-201617-data-summary)

22 Proudfoot J, Parker G, Pavlovic D, Manicavasagar V Adler E, Whitton A. Community attitudes to the appropriation of mobile phones for monitoring and managing depression, anxiety, and stress. J Med Internet Res 2010; 12: e64.

23 Batterham P, Calear A. Preferences for internet-based mental health interventions in an adult online sample: findings from an online community survey. J Med Internet Res 2017; 4: e26.

24 Johnson KR, Fuchs E, Horvath KJ, Scal P. Distressed and looking for help: internet intervention support for arthritis self-management. J Adolesc Health 2015; 56: 666-71.

25 Lal S, Daniel W, Rivard L. Perspectives of family members on using technology in youth mental health care: a qualitative study. J Med Internet Res 2017; 4: e21.

26 Grist R, Porter J, Stallard P. Mental health mobile apps for preadolescents and adolescents: a systematic review. J Med Internet Res 2017; 19: e176.

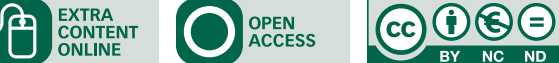

